RASĀYAN J. Chem.

Vol. 13 | No. 4 |2281-2289| October - December | 2020 ISSN: 0974-1496 | e-ISSN: 0976-0083 | CODEN: RJCABP

RJC http://www.rasayanjournal.com http://www.rasayanjournal.co.in

\title{
ISOLATION AND CHARACTERIZATION OF PHYTOCONSTITUENTS FROM STEM OF Elytranthe parasitica(L.) Danser
}

\author{
N. Kumar ${ }^{1,2}$, R. Lobo ${ }^{2, *}$ and J.E. Mathew ${ }^{3}$ \\ ${ }^{1}$ Department of Pharmacognosy, NGSM Institute of Pharmaceutical Sciences (NGSMIPS), Nitte \\ (Deemed to be University), Mangalore-575018, (Karnataka) India \\ ${ }^{2}$ Department of Pharmacognosy, Manipal College of Pharmaceutical Sciences \\ ${ }^{3}$ Department of Pharmaceutical Chemistry, Manipal College of Pharmaceutical Sciences, \\ Manipal Academy of Higher Education, Manipal -576104, (Karnataka) India \\ *E-mail: richardlobo73@gmail.com
}

\begin{abstract}
Mistletoes have earned a strong profile in treating cancer. Elytranthe parasitica (L.) Danser (EP), a hemi-parasitic plant belonging to Mistletoe family or Loranthaceae is known for its potent anti-cancer properties. Exploring the phytochemistry by isolating and characterizing phytoconstituents from unidentified mistletoes such as Elytranthe parasitica (L.) Danser would prove useful for cancer therapy. Stem parts of Elytranthe parasitica were extracted with methanol and sequentially fractionated with solvents in the increasing order of polarity. The diethyl ether fraction was selected for bioactivity guided fractionation. Fractionation was performed via gel filtration chromatography and analytical TLC to isolate the phytochemical(s). Activity guided fractionation led to the isolation of two phenolic compounds and two phytosterols: a phenolic acid (gallic acid), a flavanone (pinostrobin), a triterpenoid (lupeol) and a phytosterol (ß-sitosterol)

Keywords: Elytranthe, Isolation, Gel Permeation, NMR, Sephadex LH-20, Silica
\end{abstract}

(c) RASĀYAN. All rights reserved

\section{INTRODUCTION}

Traditional plants provide an infinite source of life-saving drugs for most of the world's population. ${ }^{1}$ Bioactive extracts and fractions from these plants yield diverse bioactive molecules that play a crucial role in combating diseases. ${ }^{2}$ An exhaustive study of phytochemicals from medicinal plants could help discover prototypes in the drug discovery process. ${ }^{3}$

Genus Elytranthe comprises many plants demonstrating strong anti-cancer activity. ${ }^{4}$ Elytranthe parasitica (L.) Danser is an annually growing parasite (Mistletoe family, Loranthaceae). Known as the parasite honeysuckle, it is found commonly on host trees such as the sacred fig, neem, mango, and jackfruit trees along the Western Ghats of India. ${ }^{5}$ Traditionally, it has been used as veterinary medicine and as a leaf paste to eradicate ticks. ${ }^{6}$ Elytranthe maingayi and Elytranthe tubaeflora, growing indigenously in Indonesia, have been traditionally used in cancer therapy. ${ }^{4}$ Accumulating evidence has found that mistletoes exhibit high antioxidant and anti-cancer activity. ${ }^{7}$ European mistletoe (Viscum Album) comprises cytotoxic compounds: lectins, viscotoxins and flavonoids ${ }^{8}$ and is extensively used as in complementary cancer therapy. A previous study on phytochemical analysis of Elytranthe parasitica indicated the presence of phytoconstituents: tannins, flavonoids, phytosterols, saponins, and carbohydrates. ${ }^{9}$ Water and alcoholic extracts of Elytranthe parasitica stem parts exhibited moderate free radical scavenging and antioxidant activity ${ }^{10}$ and inhibited Ehrlich's Ascites Carcinoma in vivo. ${ }^{11}$ However, most mistletoes species, except Viscum album have not been investigated thoroughly. Exploring the phytochemistry by isolating and characterizing from unidentified mistletoes would be valuable; this would provide an insight into the phytochemicals responsible for the bioactivity. In the present study, we endeavored to isolate and characterize phytocompounds from the dried stem of Elytranthe parasitica (L.) Danser.

Rasayan J. Chem., 13(4), 2281-2289(2020)

http://dx.doi.org/10.31788/ RJC.2020.1346062

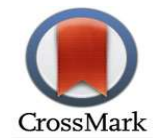


RASĀYAN J. Chem.

Vol. 13 | No. 4 |2281-2289| October - December | 2020

\section{Chemicals}

\section{EXPERIMENTAL}

Sephadex LH-20 (\#8203705543) was procured from GE Healthcare, Uppsala, Sweden. Silica gel (60-120 mesh), pre-coated HPTLC and TLC silica gel aluminum plates $60_{\mathrm{F}} 254(20 \mathrm{~cm} \times 20 \mathrm{~cm}$ with $0.2 \mathrm{~mm}$ thickness) were procured from Merck Life Sciences Ltd Pvt, Mumbai, India.

\section{Preparation of Reagents}

TLC analysis was performed by visualizing the plates in short and long ultraviolet light. The plates were derivatized by dipping in Anisaldehyde sulphuric acid [ANS] reagent and heating [120 $\left.{ }^{\circ} \mathrm{C}, 5 \mathrm{~min}\right]$.

\section{Instrumentation}

CAMAG HPTLC system (CAMAG Chemie-Erzeugnisse \& Adsorptionstechnik AG, Muttenz, Switzerland) consisting of Linomat 5, Scanner 4, UV Cabinet 4, Twin trough chambers, WinCATSV 1.2.3 software. ${ }^{1} \mathrm{H}$ and ${ }^{13} \mathrm{C}$ NMR spectroscopy was performed on Bruker $400 \mathrm{MHz}$ High-Resolution Multinuclear FT-NMR spectrometer (Bruker Corporations, Massachusetts, USA). Chemical shifts were expressed as $\delta$ (parts per million). Agilent 6250 Accurate-Mass Q-TOF (Quadrupole Time-of-Flight) MS/MS system joined to an Agilent 1200 HPLC (Agilent Technologies, California, USA) was used to record the ESI-MS spectra. FTIR spectra were recorded on a PerkinElmer System 2000 FT-IR Fourier spectrometer (PerkinElmer, Massachusetts, USA) using KBr pellets.

\section{General Procedure}

\section{Isolation of Phytoconstituents}

Stem parts of Elytranthe parasitica were extracted with methanol and sequentially fractionated with solvents in the increasing order of polarity: petroleum ether, diethyl ether, ethyl acetate, butanol and water. The diethyl ether (EP.DEE) fraction $(20 \mathrm{~g})$ was fractionated on a Sephadex LH-20 packed column using methanol via isocratic elution. The column eluents were detected by Thin Layer Chromatography (TLC) and pooled thereafter to acquire six fractions (FR 1, 2, 3, 4, 5 and 6). FR 3 (7 g) was fractionated on Sephadex LH-20 column with 100\% methanol to obtain 14 fractions (FR 3A-FR 3N). Compound 1 $(3.8 \mathrm{mg})$ was obtained by fractionating subfraction FR3 G, H $(1.90 \mathrm{~g})$ with $50 \%$ methanol: water. $1 \mathrm{~g}$ of fraction FR1 was fractionated stepwise gradient using solvent combinations petroleum ether: ethyl acetate followed by ethyl acetate: methanol to yield compound $2(3.5 \mathrm{mg})$ and compound $3(3 \mathrm{mg})$ respectively. Subfraction FR 3E $(450 \mathrm{mg})$ was fractionated on sephadex LH-20 with $100 \%$ methanol to afford compound 4 (9 mg).

\section{Detection Method}

\section{Characterization of phytoconstituents}

Chromatographic isolation of the stem parts of Elytranthe parasitica bioactive fraction yielded five phytoconstituents (Compound 1-4, Fig 1). The isolated phytoconstituents were identified and characterized by spectroscopic techniques $\left({ }^{13} \mathrm{C}\right.$ NMR, ${ }^{1} \mathrm{H}$ NMR, HR-ESI-MS, LC-ESI-MS/MS, FTIR and $\mathrm{UV}$ ) and comparing their spectral data with previously reported literature.

\section{Spectral Data}

Gallic Acid (1)

NMR: ( $\left.{ }^{1} \mathrm{H}, 400 \mathrm{MHz}, \mathrm{DMSO}\right) \delta \mathrm{ppm}: 11.89(\mathrm{COOH}), 8.8$ (H-1), $9.2(\mathrm{H}-2), 6.9$ (H-3); NMR: $\left({ }^{13} \mathrm{C}\right.$, DMSO) $\delta$ ppm: [167.71 (C-1, C=O), 145.5 (C-2), 138.1 (C-3), 120.5 (C-4), 108.8 (C-5)].

\section{Lupeol (2)}

NMR: ( $\left.{ }^{1} \mathrm{H}, 400 \mathrm{MHz}, \mathrm{DMSO}\right) \delta$ ppm: 4.67 (s, IH, H-29), 4.56 (s, IH, H-27), 3.21 (d, 1H, H-3), 2.37 (m, 1H, H-19), 1.91 (m, IH, H-21), 1.69 (s, 3H, H-30), 1.67 (t, 1H, H-13), 1.61 (s, 3H, H-2A), 1.54 (s, 3H, H2B), 1.53 (d, 1H, H-11), 1.42 (d, 1H, H-14), 1.33 (q, 1H, H-21), 1.39 (s, 1H, H-21), 1.29 (q, 1H, H-12), 1.28 (s, 1H, H-9), 1.04 (s, 1H, H-23), 1.01 (d, 1H, H-15), 0.98 (s, 3H, H-23), 0.97 (s, 3H, H-27), 0.91 (t, $1 \mathrm{H}, \mathrm{H}-18), 0.84$ (s, 3H, H-25), 0.79 (s, 3H, H-28), 0.69 (d, IH, H-5). 
RASĀYAN J. Chem.

Vol. 13 | No. 4 |2281-2289| October - December | 2020

NMR: $\left({ }^{13} \mathrm{C}, \mathrm{DMSO}\right) \delta \mathrm{ppm}: 150.80,109.32,79.02,77.27,77.01,76.76,55.31,48.72,48.32,48.00$.

\section{B-sitosterol (3)}

NMR: ( $\left.{ }^{1} \mathrm{H}, 400 \mathrm{MHz}, \mathrm{DMSO}\right) \delta$ ppm: 3.53 (tdd, IH, H-3), 5.36 (t, 1H, H-5), 0.93 (d, 3H, H-19), 0.84 (t, $3 \mathrm{H}, \mathrm{H}-24), 0.83$ (d, 3H, H-26), 0.81 (d, 3H, H-27), 0.68 (s, 3H, H-28), 1.01 (s, 3H, H-29).

\section{Pinostrobin (4)}

NMR: $\left({ }^{1} \mathrm{H}, 400 \mathrm{MHz}, \mathrm{DMSO}\right) \delta$ ppm: $5.60(1 \mathrm{H}, d d, \mathrm{H}-2), 3.12\left(1 \mathrm{H}, d d, \mathrm{H}-3_{\mathrm{ax}}\right), 2.80\left(1 \mathrm{H}, d d, \mathrm{H}-3_{\mathrm{eq}}\right), 6.04$ $(1 \mathrm{H}, d, \mathrm{H}-6), 6.08(1 \mathrm{H}, d, \mathrm{H}-8), 12.18(1 \mathrm{H}, b r, s, 5-\mathrm{OH}), 3.76\left(3 \mathrm{H}, s, 7-\mathrm{OCH}_{3}\right), 7.45\left(2 \mathrm{H}, m, \mathrm{H}-2^{\prime}, 6^{\prime}\right)$, $7.57\left(3 \mathrm{H}, m, \mathrm{H}-3^{\prime}, 4^{\prime}, 5^{\prime}\right)$,

NMR: $\left({ }^{13} \mathrm{C}\right.$, DMSO), $\delta$ ppm: 196.8 (C-4), 168.1 (C-7), 164.4 (C-5), 163.8 (C-8a), 140.0 (C-1'), 129.5 (C3',5'), $129.3\left(\mathrm{C}-4^{\prime}\right), 127.2\left(\mathrm{C}-2^{\prime}, 6^{\prime}\right), 103.0$ (C-4a), 95.0 (C-8), 94.0 (C-6), $79.2(\mathrm{C}-2), 56.0\left(7-\mathrm{OCH}_{3}\right), 43.6$ (C-3).

\section{Characterization of Isolated Compounds}

\section{RESULTS AND DISCUSSION}

Compound 1 was isolated as white crystals $(12 \mathrm{mg})$; its melting point was observed at $260^{\circ} \mathrm{C}$. We observed a downfield signal due to the carboxylic acid group at 11.89; signals due to hydroxy groups at H-3, 4 and 5 were observed at 9.15, 8.84 and 6.96 respectively in the ${ }^{1} \mathrm{H}$ NMR spectrum. In the positive mode HRMS spectra of compound 1, molecular ion peak was observed at 171.02; hence molecular mass was deduced as 170. Other major peaks were detected at 145, 193 and 610. By comparing the above spectral information with earlier literature ${ }^{12}$, compound 1 was predicted to have a molecular formula of $\mathrm{C}_{7} \mathrm{H}_{6} \mathrm{O}_{5}$ and was identified as gallic acid.<smiles>O=C(O)c1cc(O)c(O)c(O)c1</smiles>

1

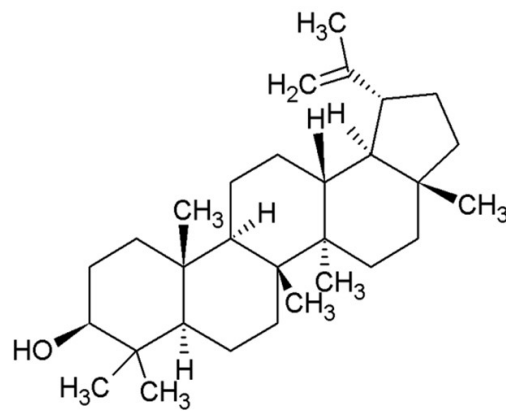

2<smiles>CC[C@H](CC[C@@H](C)[C@H]1CC[C@H]2C3CC=C4CC(O)CCC4C3CC[C@H]21)C(C)C</smiles>

3<smiles>COc1cc(O)c2c(c1)O[C@H](c1ccccc1)CC2=O</smiles>

4

Fig.-1: Isolated Compounds from Stem Parts of Elytranthe parasitica (L.) Danser (1) Gallic acid (2) Lupeol (3) B-sitosterol (4) Pinostrobin

Compound 2 was soluble in petroleum ether and was isolated as white crystals $(3 \mathrm{mg})$; its melting point was observed at $215^{\circ} \mathrm{C}$. When spotted on the TLC plate, compound 2 produced a purple color spot when 
RASĀYAN J. Chem.

Vol. 13 | No. 4 |2281-2289| October - December | 2020

sprayed with ANS reagent. Proton NMR spectroscopy indicated the occurrence of an isopropenyl moiety: vinylic proton at 4.56, 4.67 and methyl proton at 1.65. The ESI-MS (negative mode) spectrum of compound 2 gave two prominent peaks at $425.3\left(\mathrm{M}^{+} 1\right.$ peak) and $851.2\left(2 \mathrm{M}^{+} 1\right)$; the molecular mass of compound 2 was deduced as 426.

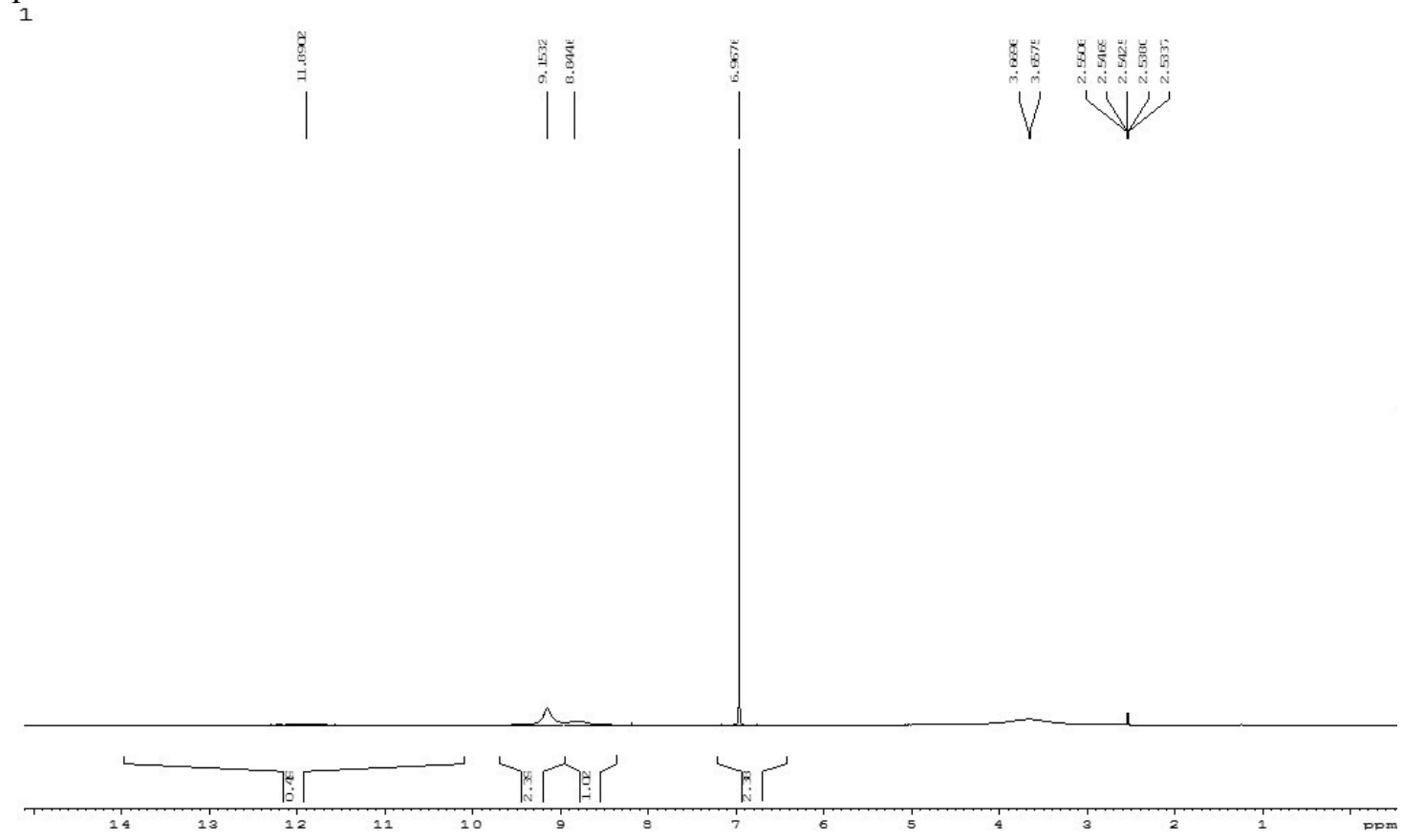

Fig.-2: ${ }^{1} \mathrm{H}$ NMR Spectrum of Compound 1

1
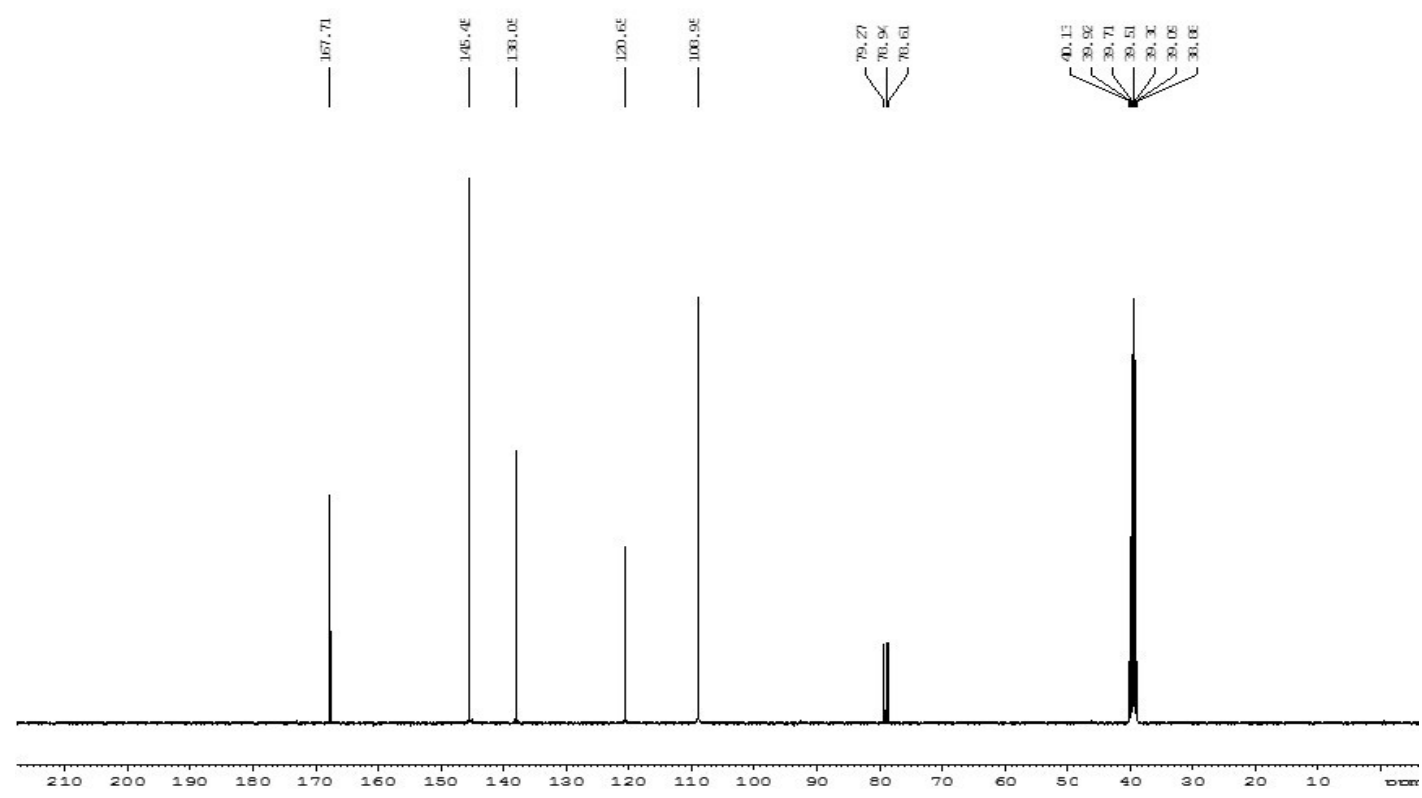

Fig.-3: ${ }^{13} \mathrm{C}$ NMR Spectrum of Compound 1

The infrared spectrum exhibited the following peaks: 1638 indicated the occurrence of conjugated carbonyl group, 3311 was due to the hydroxyl stretching, 1035 implied the occurrence of C-O. From the 
RASĀYAN J. Chem.

Vol. 13 | No. 4 |2281-2289| October - December | 2020

spectral data, the molecular formula was found to be $\mathrm{C}_{30} \mathrm{H}_{50} \mathrm{O}$. The data indicated the presence of pentacyclic triterpenoid, lupeol. ${ }^{13}$

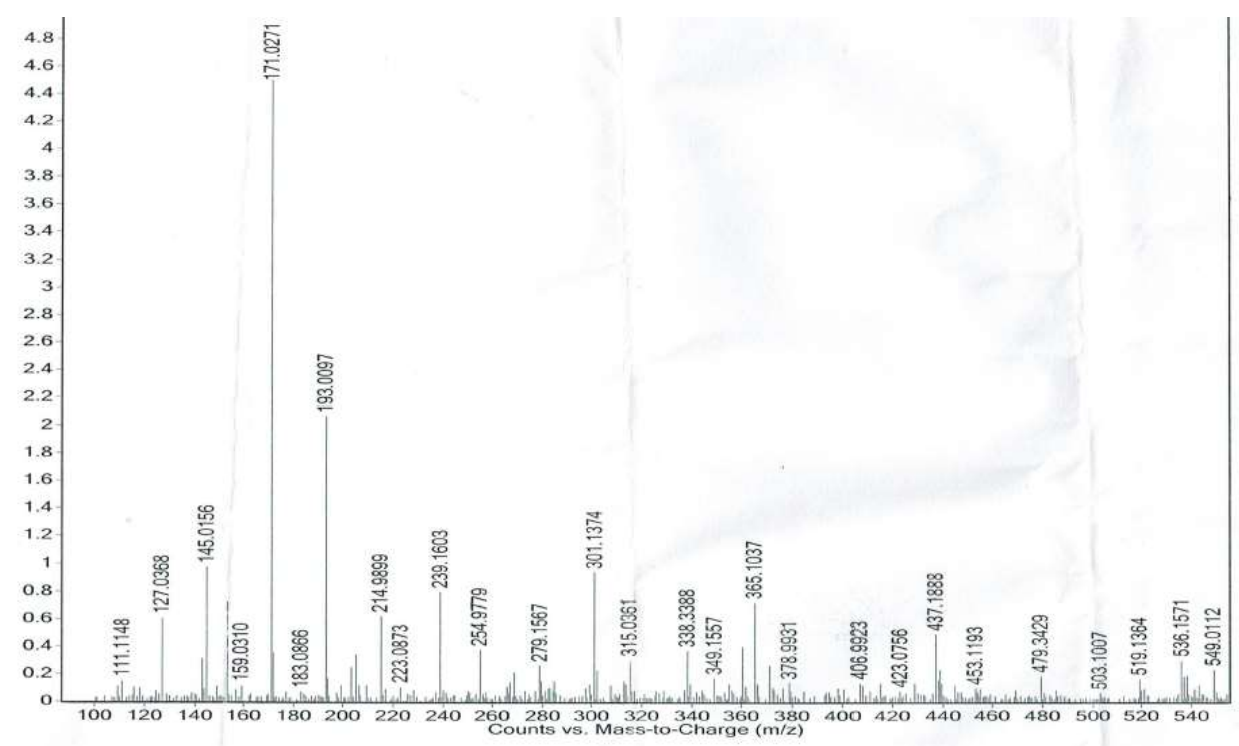

Fig.-4: HRMS Spectrum of Compound 1

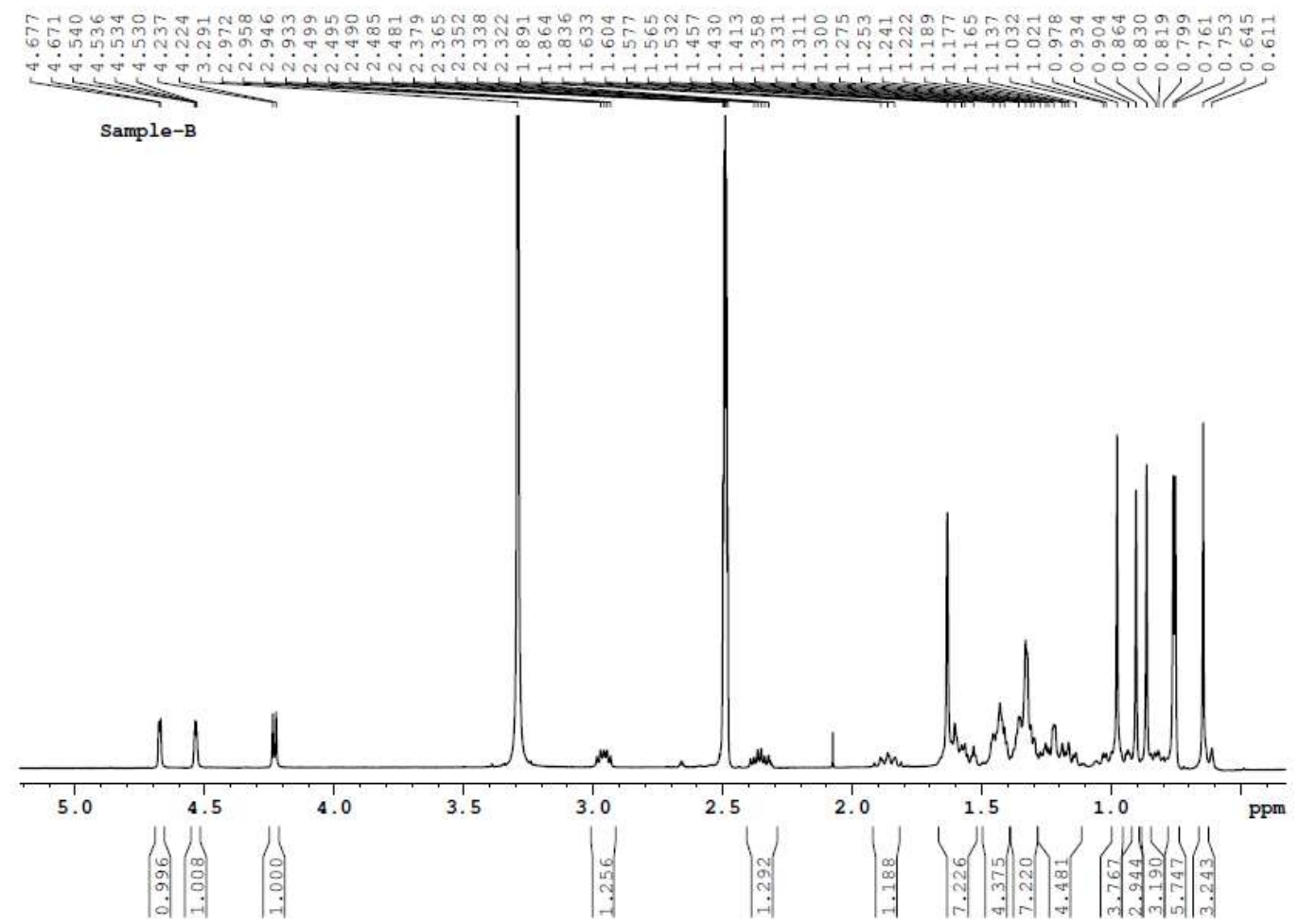

Fig.-5: ${ }^{1} \mathrm{H}$ NMR Spectrum of Compound 2

The melting point of compound $3(3.8 \mathrm{mg})$ was observed at $135^{\circ} \mathrm{C}$. A signal at $\delta \mathrm{H} 3.12 \mathrm{ppm}$ was characterized as an oxymethine proton at $\mathrm{H}-3$, a triplet signal at $\delta \mathrm{H} 5.38$ was characterized as an olefinic proton (H-6). Methyl protons were detected as singlet protons at $\delta \mathrm{H} 0.65(\mathrm{H}-18)$ and $0.83(\mathrm{H}-19)$ respectively. In the negative ESI-MS mode, major peaks were observed at 413.26(M-), 369, 364, 347 and PHYTOCONSTITUENTS OF Elytranthe parasitica(L.) Danser 2285

N. Kumar et al. 
RASĀYAN J. Chem.

Vol. 13 | No. 4 |2281-2289| October - December | 2020

408. The molecular mass was deduced as 414. The FTIR spectra presented the following peaks: 1705 denoted the occurrence of carbonyl group, 3439 was due to the hydroxyl stretching, 1058 inferred the occurrence of $\mathrm{C}-\mathrm{O}$. Based on the spectral features, compound 3 was predicted to have the molecular formula $\mathrm{C}_{29} \mathrm{H}_{50} \mathrm{O}$ and was identified as the phytosterol, $\mathrm{B}$-sitosterol. ${ }^{14}$

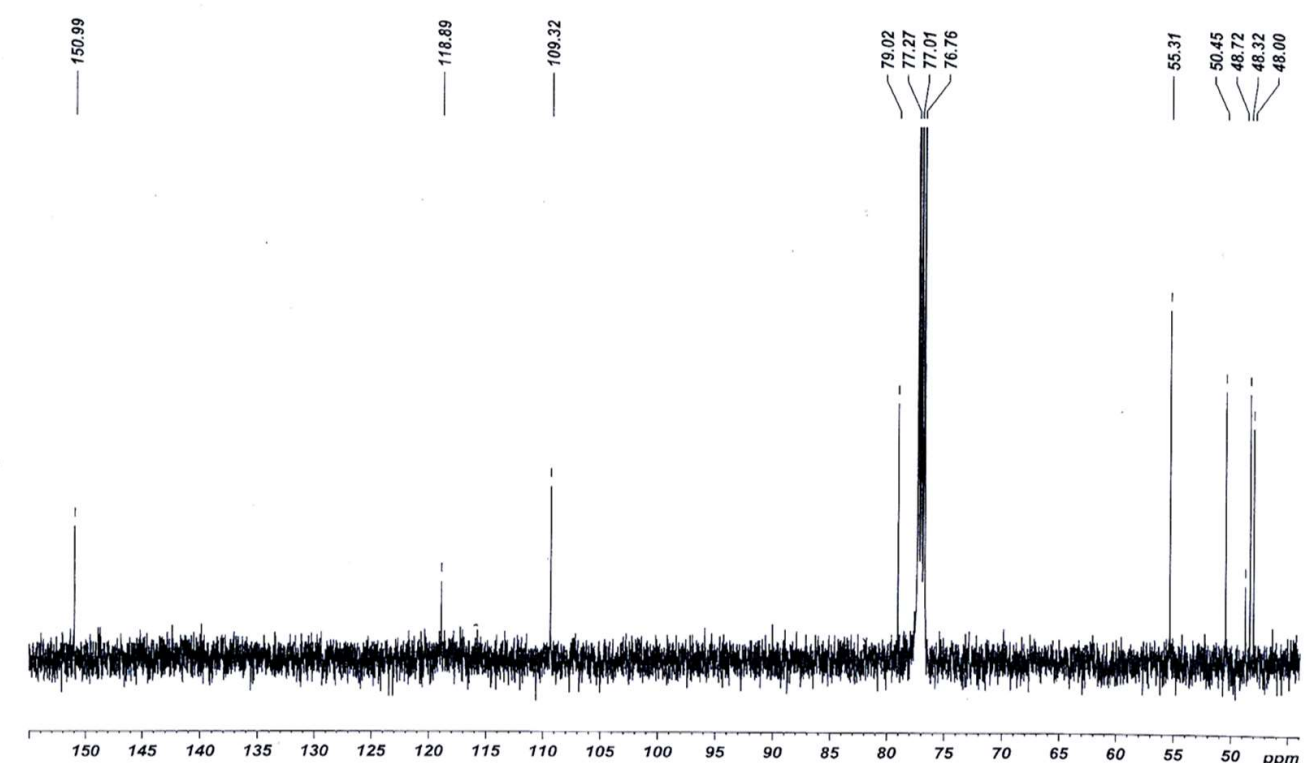

Fig.-6: ${ }^{13} \mathrm{C}$ NMR Spectrum of Compound 2

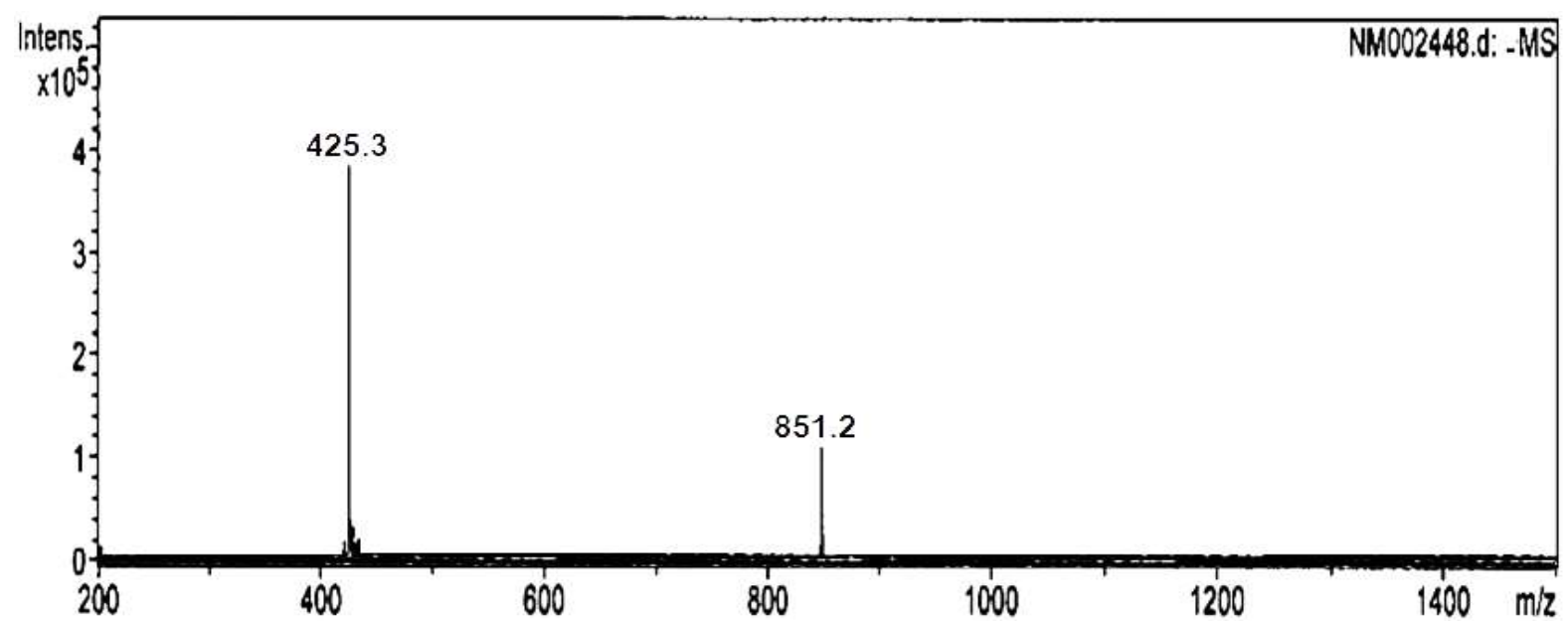

Fig.-7: ESI-MS Spectrum of Compound 2

The melting point of Compound $4(3 \mathrm{mg})$ was observed at $96-98^{\circ} \mathrm{C}$. Proton NMR spectroscopy revealed a doublet of a doublet signal at $\delta \mathrm{H} 5.60(\mathrm{H}-2)$. A singlet at $\delta 13.15$ was identified as the hydroxy group at $\mathrm{H}-5$. A multiplet signal accounting for protons at position $\mathrm{H}-3^{\prime}, 4^{\prime}, 5^{\prime}$ was observed at $\delta \mathrm{H} 7.57$. Two protons at positions H- 6 and H-8 were detected as doublets at 6.04 and 6.08 respectively. A multiplet at $\delta$ H 7.45 accounted for H-2',6'. A singlet signal at 3.76 was observed, suggesting the presence of a methoxy group at $\mathrm{H}-7$. The ${ }^{13} \mathrm{C}-\mathrm{NMR}$ spectrum showed 15 carbon atoms. On comparing with previously reported literature, compound 4 was identified as the flavonone, pinostrobin. In the ESI-MS spectrum (positive mode) of compound 4, the molecular ion peak was detected at 271. Additional peaks were 
RASĀYAN J. Chem.

Vol. 13 | No. 4 |2281-2289| October - December | 2020

detected at 293, 366 and 594. Hence, the molecular mass was deduced to be 271. The infrared spectrum exhibited the following peaks: 1655 indicated the presence of conjugate $\mathrm{C}=\mathrm{O}$ group, 3367 was due to the hydroxyl stretching, 1576 suggested the presence of aromatic $\mathrm{C}=\mathrm{C}, 1026$ indicated $\mathrm{C}=\mathrm{C}-\mathrm{H}$ stretching. From the spectral data and comparing with previously reported literature ${ }^{15}$, the molecular formula of compound 5 was deduced as $\mathrm{C}_{16} \mathrm{H}_{14} \mathrm{O}_{4}$ and it was identified as the flavonone, pinostrobin.

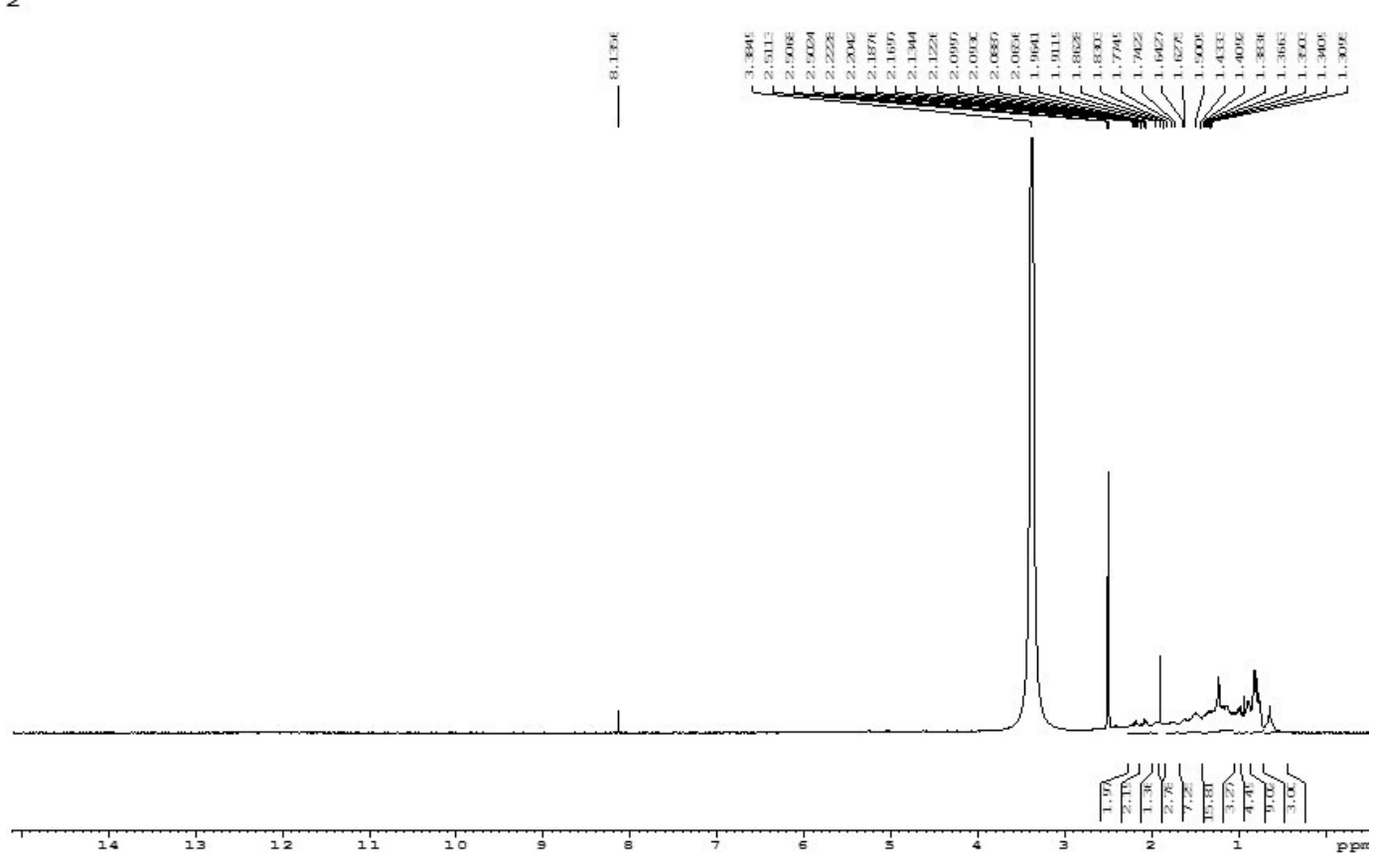

Fig.-8: ${ }^{1} \mathrm{H}$ NMR Spectrum of Compound 3

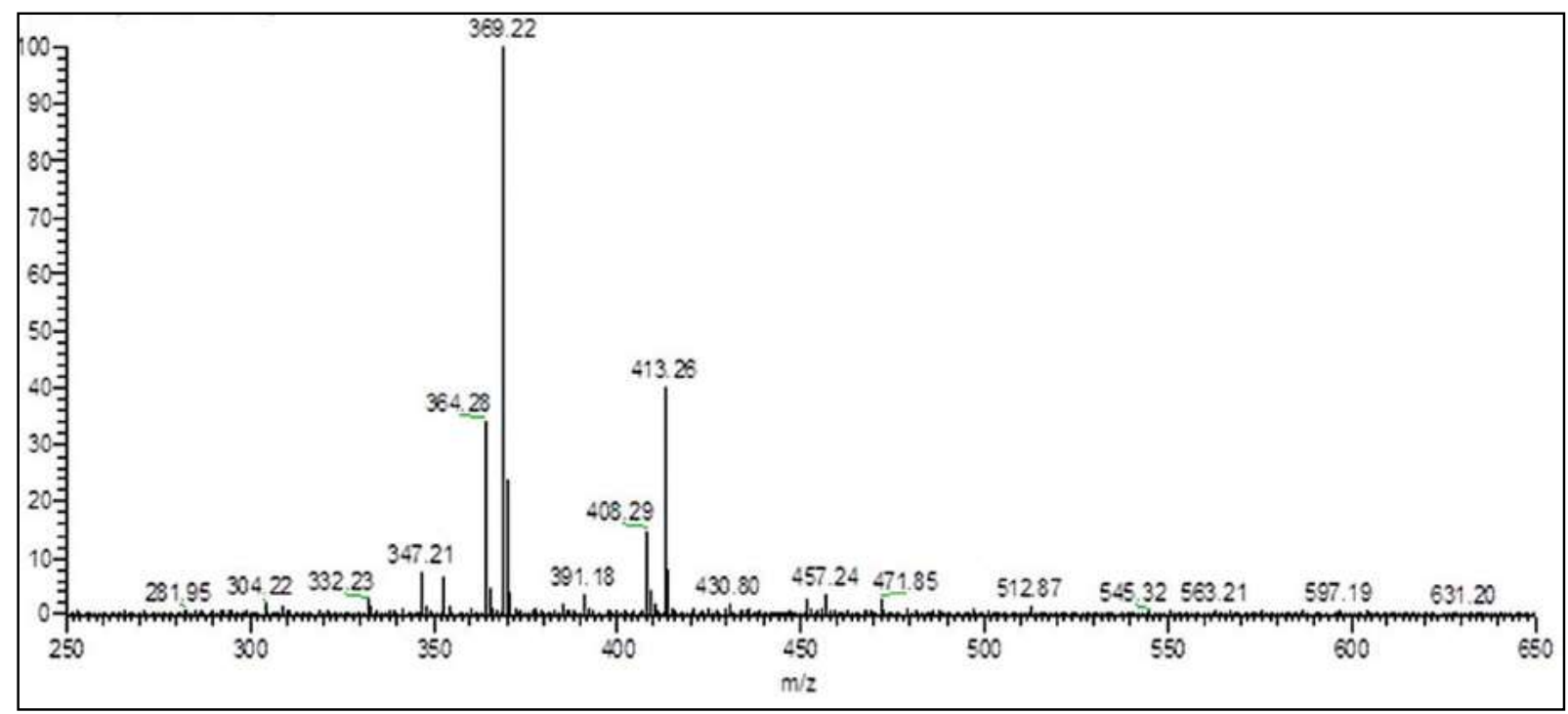

Fig.-9: ESI-MS Spectrum of Compound 3

Previous study has quantified gallic acid in Elytranthe parasitica bioactive fractions via HighPerformance Thin Layer Chromatography ${ }^{16}$; research reported in the present study validates their findings. Two flavonoids have been previously reported in the plant, pinocembrin-7-O-D-glucoside and chrysin. ${ }^{17}$ 
RASĀYAN J. Chem.

Vol. 13 | No. 4 |2281-2289| October - December | 2020

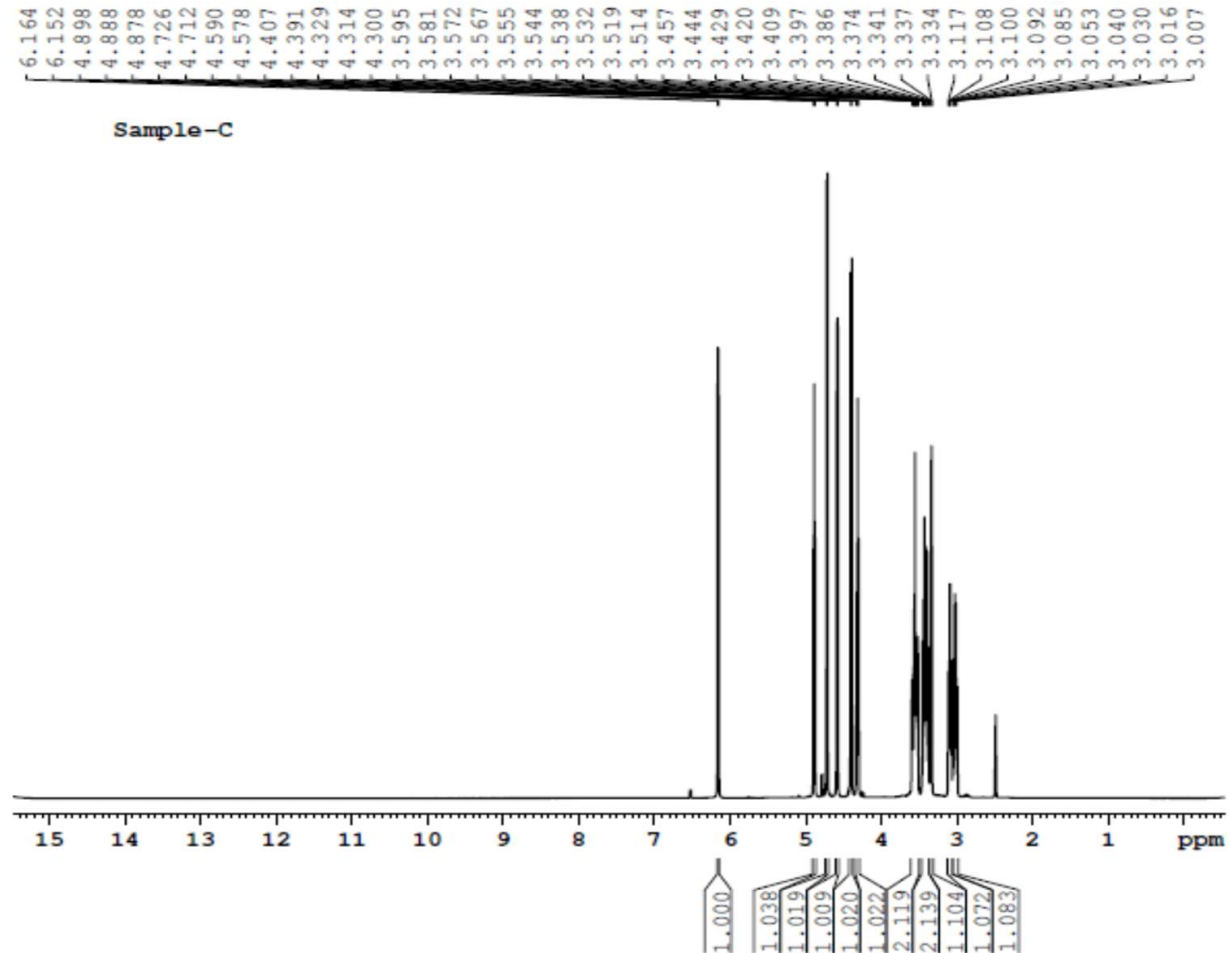

Fig.-10: ${ }^{1} \mathrm{H}$ NMR Spectrum of Compound 4

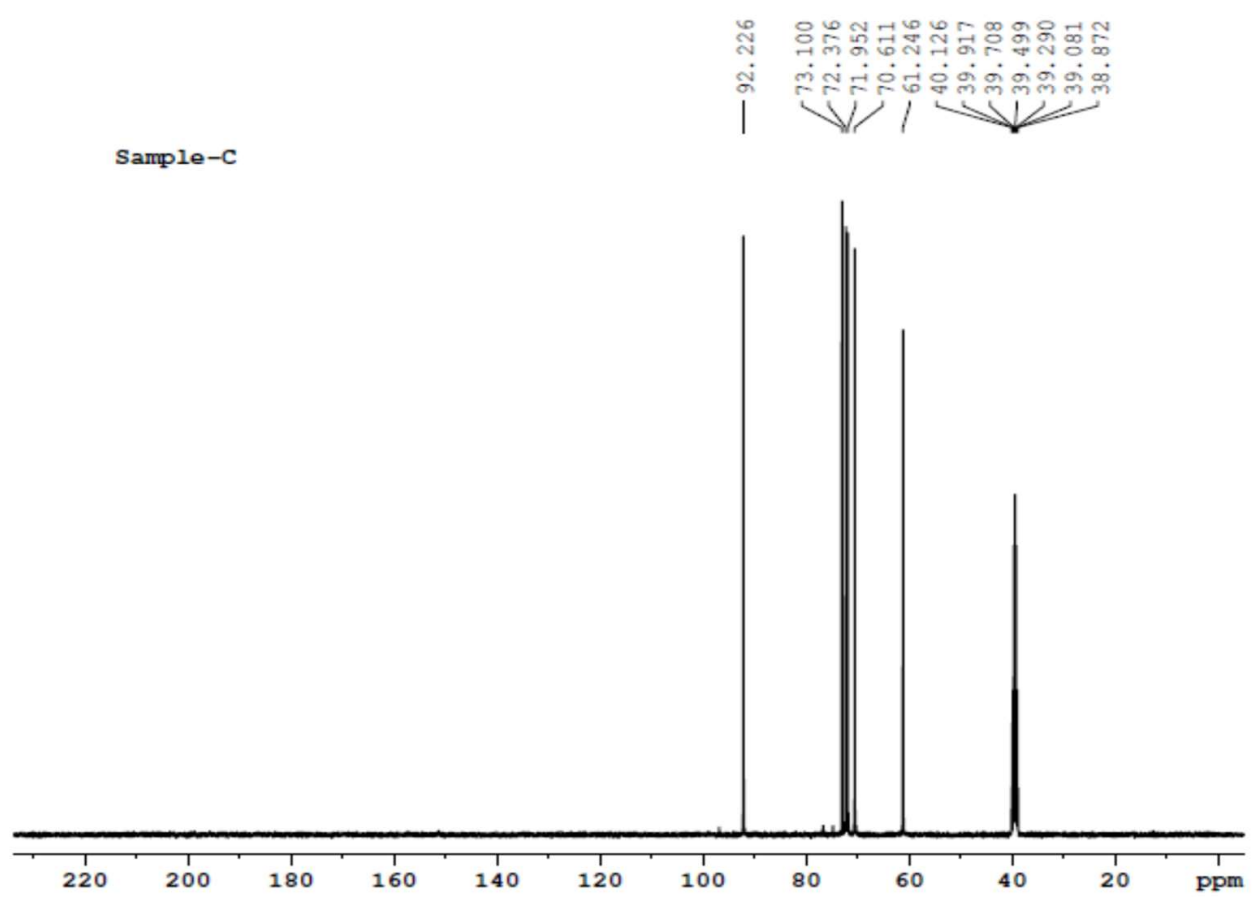

Fig.-11: ${ }^{13} \mathrm{C}$ NMR Spectrum of Compound 4 
RASĀYAN J. Chem.

Vol. 13 | No. 4 |2281-2289| October - December | 2020

\section{CONCLUSION}

We isolated four phytoconstituents: gallic acid, pinostrobin, lupeol and B-sitosterol from the stem parts of Elytranthe parasitica (L.) Danser. All constituents have been isolated and reported for the first time from genus Elytranthe and Elytranthe parasitica (L.) Danser.

\section{ACKNOWLEDGEMENT}

We are grateful to DST-SERB (Department of Science and Technology, Science and Engineering Research Board) [File no: SB/YS/LS-10/2013], Government of India for providing financial support. Our sincere thanks to Manipal College of Pharmaceutical Sciences and Manipal Academy of Higher Education for providing the infrastructural facility and resources to carry out the research work.

\section{REFERENCES}

1. R. Fierascu, I. Fierascu, A. Ortan, M. Georgiev, E. Sieniawska, Molecules, 25(2),309(2020), DOI: 10.3390/molecules 25020309

2. P. Mehta, R. Shah, S. Lohidasan, K. Mahadik, Journal of Traditional and Complementary Medicine, 5, 4, 207(2015), DOI:10.1016/j.jtcme.2014.11.041

3. B. Patwardhan, A. Vaidya, M. Chorghade, Current Science, 86, 6, 789(2004)

4. F. L. Devehat, A. Bakthiar, C. Bezivin, M. Amoros and J. Boustie, Fitoterapia, 73, 400(2002), DOI: $10.1016 / \mathrm{S} 0367-326 \mathrm{X}(02) 00125-9$

5. G. K. Bhat, Flora of Udupi, Indian Naturalist, Udupi, p.548-554 (2003)

6. U. Quattrocchi, U. CRC World Dictionary of Medicinal and Poisonous Plants: Common names, Scientific names, Eponyms, Synonyms, and Etymology, CRC Press, Florida, p. 10 (2008)

7. B. Poonthananiwatkul, R. Howard, E. Williamson, R. Lim, Journal of Ethnopharmacology, 175(4),58(2015), DOI:10.1016/j.jep.2015.08.052

8. G. Kienle, A. Glockmann, M. Schink, H. Kiene, Journal of Experimental \& Clinical Cancer Research, 28, 79(2009), DOI:10.1186/1756-9966-28-79

9. V. Sodde, N. Dashora, K. Prabhu, B. Jaykumar, R. Lobo, Der Pharmacia Sinica, 2, 217(2011)

10. V. Sodde, N. Dashora, K. Prabhu, R. Lobo, International Journal of Cancer Research, 7, 2, 135(2011), DOI:10.3923/ijcr.2011.135.143

11. V. Sodde, N. Dashora, K. Prabhu, R. Lobo, International Journal of Research in Ayurveda and Pharmacy, 2(1),207(2011)

12. S. Kamatham, N. Kumar, P. Gudipalli, Toxicology Reports, 2, 520(2015), DOI: $10.1016 /$ j.toxrep.2015.03.001

13. S. C. Gupta, S. Prasad, B. Aggarwal, Drug Discovery from Mother Nature, Springer, Medical, p.41 (2016)

14. A. Rahman, Advances in Natural Product Chemistry, Taylor \& Francis, Science, p. 498 (1992)

15. B. Burke, M. Nair, Phytochemistry, 25(6), 1427(1986), DOI:10.1016/S0031-9422(00)81303-5

16. N. Kumar, S. Biswas, A. Mathew, S. Varghese, J. Mathew, K. Nandakumar, J. Aranjani, R. Lobo, BMC Complementary and Alternative Medicine, 16, 420(2016), DOI:10.1186/s12906-016-1395-3

17. N. Kumar, A. Shrungeshwara, S. Mallik, S. Biswas, J. Mathew, J. Mathew, K. Nandakumar, R. Lobo, Anti-Cancer Agents in Medicinal Chemistry, 18, 1563(2018), DOI: $10.2174 / 1871520618666180911112127$

[RJC-6062/2020] 